\title{
Transhiatal versus Left Transthoracic Esophagectomy for Gastroesophageal Junction Cancer; The Impact of Surgical Approach on Postoperative Complications
}

\author{
Mohammad Reza Mir ${ }^{1}$, Marzieh Lashkari ${ }^{2}$, Reza Ghalehtaki ${ }^{2}$, Ali Mir ${ }^{3,}$, Amir Hossein Latif ${ }^{3}$
}

1. Department of Surgical Oncology, Cancer Institute, Tehran University of Medical Sciences, Tehran, Iran

2. Radiation Oncology Research Center, Cancer Institute, Tehran University of Medical Sciences, Tehran, Iran

3. Department of General Surgery, Dr. Shariati Hospital, Tehran University of Medical Sciences, Tehran, Iran

* Corresponding Author:

Ali Mir, MD

$9^{\text {th }}$ Ordibehesht Aly., $5^{\text {th }}$ St., Sima ie Iran St., Shahrak Gharb, Tehran, Iran

Tel: +982188077483

Fax: + 982188077526

Email: a-mir@sina.tums.ac.ir

Received: 16 Oct. 2018

Accepted: 11 Mar. 2019

\section{ABSTRACT}

\section{BACKGROUND}

Esophagectomy is the mainstay of treatment for esophageal cancer. Although different surgical approaches have been described, choosing the most appropriate technique is still on debate. We compared the complications of transhiatal esophagectomy (THE) versus left transthoracic esophagectomy (LTE) among a group of Iranian patients with gastroesophageal junction cancer.

\section{METHODS}

This was a retrospective study between 2011 and 2013 on 40 patients with gastroesophageal cancer. 23 patients underwent THE and the others underwent LTE. 30-day postoperative mortality, complications, duration of hospital stay, and number of dissected lymph nodes were studied.

\section{RESULTS}

$37.5 \%$ of the patients had squamous cell carcinoma. No mortality was seen. Totally, 10 patients suffered from complications. Cardiac and pulmonary complications occurred in eight and six patients, respectively. No patients suffered from vocal cord injuries and anastomotic leakage. The mean duration of postoperative hospital stay was $11.82 \pm 3.8$ days, and the mean number of dissected lymph nodes was $8.2 \pm 3.9$. No significant difference was seen between the two groups $(p>0.05)$.

\section{CONCLUSION}

Choosing between the approaches for resection of gastroesophageal cancer may not impact the complications and mortality rates. We propose that LTE approach could be used safely in comparison with THE, and that selecting between THE and LTE may be based on the surgeon's preference and experience.

\section{KEYWORDS:}

Esophagectomy, Gastroesophageal junction cancer, Transhiatal esophagectomy, Left transthoracic esophagectomy, Complication, Iran

Please cite this paper as:

Mir MR, Lashkari M, Ghalehtaki R, Mir A, Latif AH. Transhiatal versus Left Transthoracic Esophagectomy for Gastroesophageal Junction Cancer; The Impact of Surgical Approach on Postoperative Complications. Middle East J Dig Dis 2019;11:104-109. doi: 10.15171/ mejdd.2018.135.

\section{INTRODUCTION}

Esophageal cancer is of the 10 most prevalent malignancies worldwide and tumors of the distal parts are the most common types. In spite of the advances in the fields of chemotherapy and radiotherapy, surgery is still the mainstay of treatment. ${ }^{1,2}$

The selection of surgical technique for resection of distal esophageal cancers may influence the peri- and postoperative complications and the ultimate oncological outcome. ${ }^{3-8}$ Different surgical approaches have been introduced 
and among them, transhiatal esophagectomy (THE), and left transthoracic esophagectomy (LTE) are of the described techniques for lower third esophageal cancers. The main differences between these two approaches lie beneath the extent of lymph node dissection, complications, and direct or indirect access to and vision on the tumor.

Considering the LTE technique, the tumor is directly accessible and visible, and enough periesophageal lymph node dissection is possible. However, cardiopulmonary complications are the major limitations. ${ }^{9}$ In contrast, the THE approach has less cardiopulmonary complications and anastomotic site defects are easier to manage. ${ }^{10}$

Although choosing the appropriate surgical approach for esophagectomy is mainly on the basis of tumor location, local invasion, and surgeon's opinion and experience, the presence of complications may influence the selection. Considering the two mentioned approaches, choosing between them is still a question.

\section{MATERIALS AND METHODS}

This was a retrospective study on patients with gastroesophageal junction cancer (Siewert I and $\mathrm{II}^{11-13}$ ) who underwent esophagectomy between 2011 and 2013 at Cancer Institute, Tehran, Iran. All of these patients had received neoadjuvant chemoradiation until 8 weeks before the surgery. Of the note, none of the included patients had any underlying disease other than esophageal cancer. The operation of all patients was performed by a single surgeon either through THE or LTE approach. The patients in each group were studied for pre- and postoperative complications and mortality.

The data were collected through reviewing the patients' files during the mentioned period. Postoperative mortality was defined as a death due to surgery until 30 days after the operation. The included complications were pulmonary ones (defined as pneumonia, chylothorax, sustained chest tube secretion, and failure to wean-off from ventilator up to $5^{\text {th }}$ postoperative day), cardiac ones (defined as cardiac arrest, arrhythmia, and myocardial infarction), anastomotic leakage (defined as the presence of intestinal secretions in surgical site wound, chest tube, drains, and signs of mediastinitis and/or sepsis based on imaging findings or second surgery up to $30^{\text {th }}$ postoperative day), and vocal cord injuries (defined as postoperative hoarseness confirmed by laryngoscopic examination). Duration of postoperative hospital stay and the mean number of dissected periesophageal lymph nodes were investigated, too. To perform the statistical analysis, SPSS software (IBM Corp. Released 2011. IBM SPSS Statistics for Windows, Version 20.0. Armonk, NY: IBM Corp.) was used. A p value less than 0.05 was considered as statistically significant.

Regarding the surgical techniques; in THE approach, a midline laparotomy was performed and the abdomen was thoroughly explored to certainly assess the possibility of tumoral resection. Then, the esophagogastric junction was precisely located and the esophagus was completely mobilized in the abdomen and also in the thorax through the hiatus, then followed by gastrolysis and abdominal lymph node dissection. Finally, an incision in the neck was made and esophageal dissection in upper thoracic cavity was performed. Ultimately, reconstruction by an appropriate conduit was done.

On the other hand, in LTE approach, the patient was positioned at right lateral decubitus position and thoracotomy was performed at the left sixth intercostal space. Access to the abdomen was achieved through a diaphragmatic incision and esophageal mobilization and gastrolysis was done through the same incision. Following mediastinal lymph node dissection, esophagogastrostomy was done just below the aortic arch.

The Ethics Committee of Tehran University of Medical Sciences approved the protocol of the study regarding the ethical issues.

\section{RESULTS}

40 patients were included in this study, of them 23 underwent THE (57.5\%). The mean age of the patients was $63.6 \pm 8.3$ years and $60 \%$ were male. Considering the pathology, $37.5 \%$ had squamous cell carcinoma and others had adenocarcinoma. The details of demographic and clinical characteristics of the patients and also the TNM staging of the patients before surgery are shown in table 1.

All of the patients were alive after one month of surgery. Totally, 10 patients suffered from peri- and postoperative complications. Cardiac and pulmonary complications occurred in eight and six patients, respectively. No patients suffered from vocal cord injuries and anastomotic 
Table 1: Demographic, and clinical characteristics of the patients

\begin{tabular}{|c|c|c|c|c|c|}
\hline Variables & & THE & LTE & Total & $P$ value \\
\hline \multirow{2}{*}{ Sex, N (\%) } & Female & $14(60.8)$ & $10(58.8)$ & $24(60)$ & \multirow{2}{*}{0.896} \\
\hline & Male & $9(39.1)$ & $7(41.1)$ & $16(40)$ & \\
\hline Age, $y$, mean \pm SD & & $64 \pm 9.3$ & $63 \pm 6.9$ & $63.6 \pm 8.3$ & 0.701 \\
\hline \multirow{2}{*}{ Pathology, N (\%) } & Adenocarcinoma & $13(56.6)$ & $12(70.5)$ & $25(625)$ & \multirow{2}{*}{0.088} \\
\hline & Squamous cell carcinoma & $10(43.4)$ & $5(29.5)$ & $17(37.5)$ & \\
\hline \multirow{3}{*}{ T staging, N (\%) } & $\mathrm{T} 2$ & $7(30.4)$ & $3(17.6)$ & $10(25)$ & \multirow{3}{*}{0.159} \\
\hline & $\mathrm{T} 3$ & $15(65.2)$ & $11(64.7)$ & $26(65)$ & \\
\hline & $\mathrm{T} 4$ & $1(4.3)$ & $3(17.6)$ & $4(10)$ & \\
\hline \multirow{4}{*}{ N staging, N (\%) } & N0 & $14(60.9)$ & $6(35.3)$ & $20(50)$ & \multirow{4}{*}{0.118} \\
\hline & N1 & $5(21.7)$ & $6(35.3)$ & $11(27.5)$ & \\
\hline & $\mathrm{N} 2$ & $4(17.4)$ & $4(23.5)$ & $8(20)$ & \\
\hline & N3 & $0(0)$ & $1(5.9)$ & $1(2.5)$ & \\
\hline
\end{tabular}

LTE: left transthoracic esophagectomy; THE: transhiatal esophagectomy

Table 2: Peri- and postoperative findings of the patients

\begin{tabular}{|c|c|c|c|c|}
\hline Variables & THE & LTE & Total & $P$ value \\
\hline Complications, N (\%) & $7(30.4)$ & $7(41.1)$ & $14(35)$ & 0.423 \\
\hline Pulmonary & $4(17.4)$ & $4(23.5)$ & $8(20)$ & 0.463 \\
\hline Cardiac & $3(13)$ & $3(17.6)$ & $6(15)$ & 0.511 \\
\hline Vocal cord injury & $0(0)$ & $0(0)$ & $0(0)$ & NA \\
\hline Anastomotic leakage & $0(0)$ & $0(0)$ & $0(0)$ & NA \\
\hline 30-day mortality, N (\%) & $0(0)$ & $0(0)$ & $0(0)$ & NA \\
\hline Hospital stay, $\mathrm{d}$, mean $\pm \mathrm{SD}$ & $11.82 \pm 3.8$ & $11 \pm 3.2$ & $12.8 \pm 4.4$ & 0.140 \\
\hline Number of dissected lymph nodes, mean \pm SD & $8.2 \pm 3.9$ & $7.9 \pm 4$ & $8.6 \pm 3.8$ & 0.588 \\
\hline
\end{tabular}

LTE: left transthoracic esophagectomy; THE: transhiatal esophagectomy

leakage. Considering the peri- and postoperative complications, no significant difference was seen between the two groups $(p>0.05)$. The details of occurred complications are shown in table 2 .

The mean duration of postoperative hospital stay was $11.82 \pm 3.8,11 \pm 3.2$, and $12.8 \pm 4.4$ days in all patients, and patients in the THE, and LTE groups, respectively $(p>0.05)$. The mean number of dissected lymph nodes was $8.2 \pm 3.9,7.9 \pm 4$, and $8.6 \pm 3.8$ in all patients, and patients in the THE, and LTE groups, respectively $(p>0.05)$.

\section{DISCUSSION}

The prevalence of gastroesophageal cancer is still increasing worldwide, and considering the higher prevalence of this disease in Iran, ${ }^{14}$ which is the most western point of the Silk Road - as known as the Asian Esophageal
Cancer Belt- employing the best treatment strategy is mandatory to improve the outcomes. Esophagectomy is still the mainstay of treatment for gastroesophageal cancers. ${ }^{1-2}$ Of the described surgical approaches, THE and LTE are of the favorable approaches. ${ }^{15-17}$ Although the LTE approach is not as popular as other approaches, it is even somehow superior in some aspects to a traditionally favorable technique of right transthoracic esophagectomy. ${ }^{18}$ However, the most appropriate technique is still open to debate even among the experts in this field. ${ }^{19}$ Herein, we have studied the peri- and postoperative complications and mortality rates among Iranian patients who underwent either THE or LTE.

A meta-analysis of studies on 1155 patients with gastroesophageal cancer showed that THE resulted in decreased pulmonary complications more than transtho- 
racic esophagectomy, which is in accordance with the results of a recent study on 4053 patients. ${ }^{15,20}$ However, another study on 942 patients showed no difference between the two approaches regarding pulmonary complications. ${ }^{21}$ In our study, we found no significant difference between THE and LTE groups considering peri- and postoperative pulmonary complications.

Most of the previous studies concluded that the frequency of cardiovascular complications after transhiatal and transthoracic esophagectomy are similar. ${ }^{15,20-21}$ Among our patients, six patients suffered from peri- and postoperative cardiac complications. However, the difference between the two groups was not significant.

Anastomotic leakage is the most catastrophic complication after esophagectomy. Some of the previous studies have shown that anastomotic leakage occurs less frequently after transthoracic esophagectomy. ${ }^{22-24}$ However, recent studies have concluded that there is no significant difference between the two groups regarding anastomotic leakage. ${ }^{15,20-21}$ Fortunately, we encountered no occurrence of such incidents. Also none of our patients suffered from vocal cord injuries after either THE or LTE.

Considering the overall frequency of peri-and postoperative complications, we found no significant difference between the two groups.

The mean duration of hospital stay was similar in the two groups in our study. However, this duration was significantly longer among the patients who underwent transthoracic esophagectomy rather than transhiatal esophagectomy based on the previous studies. ${ }^{20-21}$ The absolute mean hospital stay of our patients was similar to the findings of previous studies, though. ${ }^{21,25-27}$

An important prognostic factor for gastroesophageal cancer is lymph node clearance. Removal of these lymph nodes is mandatory to reach the goals of the surgery. ${ }^{20}$ However, the sufficient extent of lymph node dissection is still on debate. ${ }^{28} \mathrm{~A}$ recent study has shown that patients who underwent transthoracic esophagectomy had significantly more lymph nodes removed than those who underwent transhiatal esophagectomy. ${ }^{16}$ However, some other studies showed no difference between the two groups. ${ }^{20,26,29-30}$ Concordantly, we found no significant difference between the two groups regarding the mean number of dissected lymph nodes.

Fortunately, we encountered no cases of postoperative deaths. Most of previous studies found no significant difference between the two groups regarding postoperative deaths and patients' survival. ${ }^{15-16,21}$ However, a metaanalysis in 2014 showed that transhiatal esophagectomy led to lower 30-day postoperative mortality rates. ${ }^{20}$

Considering the findings of this study, LTE as a more invasive technique than THE could be used as a safe method of esophagectomy. On the other hand, our results are assuring regarding enough lymph node dissection through THE. Therefore, we concluded that each of these two techniques can be implicated based on the patient's situation and characteristics, and also the surgeon's preference and experience.

Our study was limited in some ways. First, this was a retrospective study with its potential weaknesses. Second, the sample size of the study was small. However, it should be emphasized that we excluded a notable number of patients with significant previous medical illnesses to minimize the potential selection bias on the peri- and postoperative complications. Third, the follow-up period could be longer. However, it should be considered that calculating the long-term patient survival was not of the aims of our study. Regardless of these limitations, it should be considered that this is of few studies that compared the benefits and limitations of LTE with THE. We recommend future comprehensive prospective studies with larger sample size and longer follow-up periods.

As a conclusion, we found no significant difference between THE and LTE regarding peri- and postoperative complications, mean number of dissected lymph nodes, mean duration of hospital stay, and post-operative mortality rates. Therefore, we suggest that choosing between the approaches for resection of gastroesophageal cancer may not impact peri- and postoperative complications and mortality rates. We propose that the LTE approach could be used safely in comparison with THE, and that selecting between THE and LTE may be based on the surgeon's preference and experience.

\section{ETHICAL APPROVAL}

There is nothing to be declared.

\section{CONFLICT OF INTEREST}

The authors declare no conflict of interest related to this work. 


\section{REFERENCES}

1. Cao X, Xiao J, Wang S, Wu B, Huang Z, Huang S, et al. The potential function of transhiatal esophagectomy in the treatment of esophageal carcinoma. Chin Ger J Clin Oncol 2008;7:31-4. doi:10.1007/s10330-007-0151-z.

2. Hulscher JB, van Sandick JW, de Boer AG, Wijnhoven B, Tijssen J, Fockens P, et al. Extended transthoracic resection compared with limited transhiatal resection for adenocarcinoma of the esophagus. $N \mathrm{Engl} \mathrm{J} \mathrm{Med}$ 2002;347:1662-9. doi:10.1056/NEJMoa022343.

3. Suttie SA, Li AG, Quinn M, Park KG. The impact of operative approach on outcome of surgery for gastro-oesophageal tumours. World J Surg Oncol 2007;5:95. doi: 10.1186/1477-7819-5-95.

4. Goldminc M, Maddern G, Le Prise E, Meunier B, Campion JP, Launois B. Oesophagectomy by a transhiatal approach or thoracotomy: a prospective randomized trial. Br J Surg 1993;80:367-70. doi:10.1002/bjs.1800800335.

5. Chu KM, Law SY, Fok M, Wong J. A prospective randomized comparison of transhiatal and transthoracic resection for lower-third esophageal carcinoma. Am J Surg 1997;174:320-4. doi:10.1016/S0002-9610(97)00105-0.

6. Dexter SP, Sue-Ling H, McMahon MJ, Quirke P, Mapstone N, Martin IG. Circumferential resection margin involvement: an independent predictor of survival following surgery for oesophageal cancer. Gut 2001;48:667-70.

7. Mulligan ED, Dunne B, Griffin M, Keeling N, Reynolds JV. Margin involvement and outcome in oesophageal carcinoma: a 10-year experience in a specialist unit. Eur J Surg Oncol 2004;30:313-7. doi:10.1016/j. ejso.2003.11.009.

8. Ito H, Clancy TE, Osteen RT, Swanson RS, Bueno R, Sugarbaker DJ, et al. Adenocarcinoma of the gastric cardia: what is the optimal surgical approach? J Am Coll Surg 2004;199:880-6. doi:10.1016/j.jamcollsurg.2004.08.015.

9. Kim SH, Lee KS, Shim YM, Kim K, Yang PS, Kim TS. Esophageal resection: indications, techniques, and radiologic assessment. Radiographics 2001;21:1119-37. doi: 10.1148/radiographics.21.5.g01se031119.

10. Smithers BM, Gotley DC, Martin I, Thomas JM. Comparison of the outcomes between open and minimally invasive esophagectomy. Ann Surg 2007;245:232-40. doi: 10.1097/01.sla.0000225093.58071.c6.

11. Siewert JR, Hölscher AH, Becker K, Gössner W. [Cardia cancer: attempt at a therapeutically relevant classification.] Chirurg 1987;58:25-32.

12. Siewert JR, Stein HJ. Carcinoma of the gastroesophageal junction - classification, pathology and extent of resection. Dis Esophagus 1996;9:173-82. doi:10.1093/ dote/9.3.173.
13. Siewert JR, Stein HJ. Classification of adenocarcinoma of the oesophagogastric junction. Br J Surg 1998;85:14579. doi:10.1046/j.1365-2168.1998.00940.x.

14. Mosavi-Jarrahi A, Mohagheghi MA. Epidemiology of esophageal cancer in the high-risk population of Iran. Asian Pac J Cancer Prev 2006;7:375-80.

15. Schlottmann F, Strassle PD, Patti MG. Transhiatal vs. Transthoracic Esophagectomy: A NSQIP Analysis of Postoperative Outcomes and Risk Factors for Morbidity. $J$ Gastrointest Surg 2017;21:1757-63. doi:10.1007/s11605017-3572-1.

16. Łochowski M, Łochowska B, Kozak J. Transthoracic versus transhiatal esophagectomy - influence on patient survival. Prz Gastroenterol 2017;12:118-21. doi:10.5114/ pg.2016.64609.

17. Brown AM, Giugliano DN, Berger AC, Pucci MJ, Palazzo F. Surgical approaches to adenocarcinoma of the gastroesophageal junction: the Siewert II conundrum. Langenbecks Arch Surg 2017;402:1153-8. doi: 10.1007/ s00423-017-1610-9.

18. Ma Q, Liu W, Long H, Rong T, Zhang L, Lin Y, et al. Right versus left transthoracic approach for lymph node-negative esophageal squamous cell carcinoma. J Cardiothorac Surg 2015;10:123. doi:10.1186/s13019-015-0328-4.

19. Haverkamp L, Seesing MF, Ruurda JP, Boone J, V Hillegersberg R. Worldwide trends in surgical techniques in the treatment of esophageal and gastroesophageal junction cancer. Dis Esophagus 2017;30:1-7. doi:10.1111/dote.12480.

20. Wei MT, Zhang YC, Deng XB, Yang TH, He YZ, Wang ZQ. Transthoracic vs transhiatal surgery for cancer of the esophagogastric junction: a meta-analysis. World J Gastroenterol 2014;20:10183-92. doi:10.3748/wjg.v20.i29.10183.

21. Khullar OV, Jiang R, Force SD, Pickens A, Sancheti MS, Ward K, et al. Transthoracic versus transhiatal resection for esophageal adenocarcinoma of the lower esophagus: A value-based comparison. J Surg Oncol 2015;112:51723. doi:10.1002/jso.24024.

22. Boshier PR, Anderson O, Hanna GB. Transthoracic versus transhiatal esophagectomy for the treatment of esophagogastric cancer: a meta-analysis. Ann Surg 2011;254:894906. doi:10.1097/SLA.0b013e3182263781.

23. Kawoosa NU, Dar AM, Sharma ML, Ahangar AG, Lone GN, Bhat MA, et al. Transthoracic versus transhiatal esophagectomy for esophageal carcinoma: experience from a single tertiary care institution. World $J$ Surg 2011;35:1296-302. doi:10.1007/s00268-011-1020-z.

24. Ryan CE, Paniccia A, Meguid RA, McCarter MD. Transthoracic Anastomotic Leak After Esophagectomy: Current Trends. Ann Surg Oncol 2017;24:281-90. doi: 10.1245/s10434-016-5417-7. 
25. Sasako M, Sano T, Yamamoto S, Sairenji M, Arai K, Kinoshita $\mathrm{T}$, et al. Left thoracoabdominal approach versus abdominal-transhiatal approach for gastric cancer of the cardia or subcardia: a randomised controlled trial. Lancet Oncol 2006;7:644-51. doi:10.1016/S14702045(06)70766-5.

26. Morgan MA, Lewis WG, Hopper AN, Escofet X, Havard TJ, Brewster AE, et al. Prospective comparison of transthoracic versus transhiatal esophagectomy following neoadjuvant therapy for esophageal cancer. Dis Esophagus 2007;20:225-31.

27. Rentz J, Bull D, Harpole D, Bailey S, Neumayer L, Pappas T, et al. Transthoracic versus transhiatal esophagectomy: a prospective study of 945 patients. $J$ Thorac Cardiovasc Surg 2003;125:1114-20. doi:10.1067/mtc.2003.315.

28. Gronnier C, Piessen G, Mariette C. Diagnosis and treatment of non-metastatic esophagogastric junction adenocarcinoma: what are the current options? J Visc Surg 2012;149:e23-33. doi:10.1016/j.jviscsurg.2012.01.003.

29. Wang LS, Wu CW, Hsieh MJ, Fahn HJ, Huang MH, Chien KY. Lymph node metastasis in patients with adenocarcinoma of gastric cardia. Cancer 1993;71:194853. doi:10.1002/1097-0142(19930315)71:6<1948::AIDCNCR2820710604>3.0.CO;2-S.

30. Dresner SM, Lamb PJ, Bennett MK, Hayes N, Griffin SM. The pattern of metastatic lymph node dissemination from adenocarcinoma of the esophagogastric junction. Surgery 2001;129:103-9. doi:10.1067/msy.2001.110024. 